\title{
Clinicopathological Investigation of Foot and Mouth Disease and Serotype Identification of the Viruses in Cattle of Bangladesh
}

\author{
Mohammad Shahidul Islam ${ }^{1}$, Mohammed Ahasan Habib ${ }^{1}$, Mohammad Rafiqul Islam², \\ Mohammad Showkat Mahmud ${ }^{3}$, Provat Chandra Saha ${ }^{4}$, Tahmina Ruba ${ }^{4}$, Priya Mohan Das ${ }^{4}$, \\ Mohammad Abu Hadi Khan ${ }^{4, *}$ \\ ${ }^{2}$ Bangladesh Agricultural Research Council, Dhaka, Bangladesh \\ ${ }^{3}$ Animal Health Research Division, Bangladesh Livestock Research Institute, Savar, Dhaka-1341, Bangladesh \\ ${ }^{4}$ Department of Pathology, Faculty of Veterinary Science, Bangladesh Agricultural University, Mymensingh, Bangladesh
}

Copyright $\bigcirc 2017$ by authors, all rights reserved. Authors agree that this article remains permanently open access under the terms of the Creative Commons Attribution License 4.0 International License

\begin{abstract}
Foot and Mouth Disease (FMD) is a highly contagious viral disease of farm animals. This study was aimed to identify symptoms, characteristics pathology and viral serotypes involved in infected cattle of Bangladesh. Dominant signs observed were salivation, vesicular eruption, lameness and maggot infestations in $66 \%, 80 \%$, $36 \%$ and $14 \%$ cattle respectively. Out of 202 infected cattle investigated, 35 were below six months of age. A total of 18 young calves and 8 adult cattle were died due to FMD. Seven young calves and two adult cattle were examined at necropsy, 'Tiger heart disease' was commonly seen both in the young and adult cattle. The 'currant jelly clot' was common in the atrium, ventricles, aorta and veins of the heart of adult cattle. Congested and consolidated lungs, atrophied spleen, and fibrosed udder were grossly seen in the infected and dead cattle. Microscopically, hyalinization of cardiac muscle in young calf and degeneration, necrosis and multifocal lymphocytic infiltration in heart muscle were suggestive for infectivity due to FMD viruses. There were bronchiolitis, pulmonary emphysema, interstitial pneumonia and thickening of interlobular septa of lungs. Cattle survived from the acute infection developed respiratory distress in $15 \%$ cattle. Out of 202 samples tested in reverse transcriptase polymerase chain reaction (RT-PCR), 187 samples found to generate positive amplicons. Single infectivity due to FMD viral Serotypes $\mathrm{O}, \mathrm{A}$ and Asia 1 were seen in $115(62 \%), 26(14 \%)$ and 34 $(18 \%)$ cases, respectively. Seven cattle were co-infected with FMD viral Serotypes $O$ and Asia 1 and four with FMD viral Serotypes $O$ and A. FMD viral serotype $O$ was dominating in cattle all over the country and was related to death of infected young and adult cattle. Cardiac myonecrosis and respiratory failure were the dominant lesions may be related to death of infected animals.
\end{abstract}

Keywords FMD, Vesicles, Cardiac myonecrosis, Currant Jelly Clot, Heart Failure, Viral Serotypes

\section{Introduction}

Foot and mouth disease (FMD) is a highly contagious and transboundary viral disease of domesticated and wild cloven-hoofed animals showing symptoms of fever, erosions and ulceration onto the hooves, lips, mouth, teats, snout and tongue. Outbreak of FMD is associated with huge economic loss to the global livestock industry $[1,2]$. The causal agent, FMD virus (FMDV) is consisting of single-stranded positive sense RNA genome that possesses high potential for genetic and antigenic variation. There are seven recognized serotypes (O, A, C, SAT1, SAT2, SAT3 and Asia1) and about 65 subtypes of FMDV [3]. The disease is endemic in Bangladesh but took an epidemic proportion after a gap of few years. Annual loss due to FMD in Bangladesh was estimated to be around US\$125 million [4]. Direct loss in lactating animals is due to reduction (25-50\%) of total yield. Moreover, the disease is a leading cause of infertility, abortion, mortality and reduced efficiency of working animals, infected animals hardly attain their original production potential $[5,6]$. The disease has direct and indirect economic consequences resulting from constraints in international trade in animals and animal products originating from infected countries. Despite vaccination, outbreak of FMD has been a regular event throughout the country each year. Though the exact reason for frequent outbreak of the disease is not very clear, but it may be due to new introduction of mutant viruses as a 
result of inappropriate serotypes used for vaccine preparation or regular importation of the vaccines of heterogeneous strain from abroad. Moreover a significant number of cattle and buffaloes have been entering in Bangladesh from neighboring country(s) every year either through proper or improper channels, which directly or indirectly serve a pathway for new virus introduction. Almost every year, new outbreaks of FMD occur in different parts of Bangladesh. Though some recent outbreaks resembled that adult case fatality is occurring along with calf fatality but the reason is still unknown. On the other hand, FMD vaccine (public, private or imported) is also being used in the field but new field virus prevailing in Bangladesh was not used as vaccine strain. These vaccines from different sources may not cover the genetic and antigenic requirement. Antigenic variation among FMD viruses circulating in the field can reduce the protective capacity of vaccines and it is, therefore, important to monitor the relationship between field strains and vaccine strains in use [7]. Due to mutation of FMD viruses, the pathogenicity and pathology could have changed. So, it is necessary to observe the clinical signs, gross and microscopic changes in the tissue level following natural infection of FMD in cattle.

Sero-epidemiological investigation of FMD virus in cattle population indicated that four Serotypes (A, O, C and Asia 1) of FMDV were prevailing in Bangladesh during 1960 to 1990 [8]. FMDV Asia 1 serotype was detected in 1987 and 1996 and FMDV C was lastly reported in Bangladesh in 1992 [9]. Type A and type O viruses were identified between 1987 and 1997 in Bangladesh [10] and again between 1998 and 2000 [11]. Only Serotype O was isolated in 2000-2001 in various parts of Bangladesh [12]. Therefore, it is essential to monitor the viral serotypes involved in the disease process on a regular basis. This study was, therefore, aimed to study the lethal pathology of FMD and identify the serotypes prevailing in Bangladesh.

\section{Materials and Methods}

\subsection{Investigation of Natural Outbreaks of FMD}

Natural outbreaks of FMD in seven divisions of Bangladesh were investigated after intimating from the Department of Livestock Services (DLS), Bangladesh during the period 2013-2014. A total of 202 infected cattle were investigated. The characteristic clinical signs were recorded. The cardiac and respiratory activities were observed by using a stethoscope. The rectal temperature of infected cattle was determined using a thermometer (Fahrenheit).

\subsection{Necropsy of Dead Animals and Sample Collection}

Calves $(n=7)$ and adult $(n=2)$ cattle died due to FMD were investigated at necropsy. The animals infected and died were collected from the natural outbreaks areas of Tangail, Pabna, Moulvi Bazaar, Mymensingh and Dinajpur district, Bangladesh. The animals were necropsied by using standard protocol [13]. Lesions in the oral cavity, hooves, hearts, udder, lungs and other internal organs were observed carefully, documented by capturing images and representative tissue samples were collected in 10 percent neutral buffered formalin for histopathological investigation.

\subsection{Histopathological investigation}

Formalin fixed tissues from the oral and pedal tissues, lungs, liver, kidney, spleen, pancreas, and heart were processed. The tissue sections were cut into 4 to $6 \mu$ thickness and stained with Haematoxylin and Eosin (H\&E) and Goldner's trichrome staining $[14,15]$. The slides were mounted using DPX, air dried and examined under microscope at low (10X) and high power (40X) microscopic field. The images of lesions were captured using automated computer (Microimaging, Carl Zeiss, $\mathrm{GmbH}$, Germany) connected with the microscope and ZEN lite 2012 software.

\subsection{Identification of FMD viral serotypes}

Multiplex RT-PCR was adapted to detect serotype specific amplicons [16]. Tissue samples were collected from the oral/pedal lesions of infected cattle, extracted viral RNA using RNeasy Mini Kit (Qiagen \#74106). A total of 40 cycles of amplification reaction was carried out by using each sample [17]. The RT-PCR amplicons were electrophoresed in agarose gel to visualize the fragment of genes and to identify the viral serotype involved.

\section{Results}

\subsection{Clinical Investigation of Sick Animals}

A total of 202 infected cattle were investigated during 2013-2014 in seven divisions of Bangladesh (Table 1), characteristics clinical signs observed were salivation, vesicular eruption, lameness and maggot infestation in $66 \%, 80 \%, 36 \%$ and $14 \%$ cattle respectively (Table 1 ). The vesicular lesions ruptured easily leading to the formation of ulcers in gum and tongue (Figure 1a and 1c). The tongue papillae were degenerated, necrosed and appeared projecting (Figure 1b). The hooves lesion was characterized by erosion, ulceration and deformities of hooves (Figure 2). Fever $\left(104^{\circ}-105^{\circ} \mathrm{F}\right)$ was noted in all of the infected young and adult cattle. The infected cattle showed much depression, smacking of the lips, grinding of the teeth, nasal discharge, shaking/kicking of the feet. Mastitis was also evident in the affected cows. Scanty oral 
and pedal lesions were seen in the calves investigated increase in respiratory rate and died later on $(\mathrm{N}=18$, Figure $(\mathrm{n}=35)$. The infected young calves appeared depressed, on $3 \mathrm{a}$ and $3 \mathrm{~b})$. auscultation showed cardiac arrhythmia, tachycardia,

Table 1. Clinical investigation of FMD affected cattle in different divisions of Bangladesh. Out of 202 infected cattle investigated, 35 were below six months of age. A total of 18 calves and 08 adult cattle (in bracket, ") were died due to FMD

\begin{tabular}{|c|c|c|c|c|c|c|}
\hline \multirow{2}{*}{ Name of Division } & \multirow{2}{*}{$\begin{array}{c}\text { Number of cattle } \\
\text { investigated }\end{array}$} & \multicolumn{5}{|c|}{ Clinical signs } \\
\hline & & Salivation & Vesicular lesion & Lameness & $\begin{array}{c}\text { Maggot } \\
\text { infestation }\end{array}$ & Dead cattle \\
\hline Barishal & 21 & 11 & 18 & 6 & 4 & $2\left({ }^{*} 0\right)$ \\
\hline Chittagong & 24 & 12 & 24 & 5 & 0 & $3\left({ }^{*} 1\right)$ \\
\hline Dhaka & 54 & 38 & 35 & 16 & 6 & $8\left({ }^{*} 3\right)$ \\
\hline Khulna & 22 & 15 & 21 & 8 & 1 & $4\left({ }^{*} 1\right)$ \\
\hline Rajshahi & 35 & 27 & 33 & 15 & 8 & $5\left({ }^{*} 2\right)$ \\
\hline Rangpur & 21 & 14 & 18 & 9 & 6 & $2\left(\left(^{*} 1\right)\right.$ \\
\hline Sylhet & 25 & 17 & 21 & 14 & 3 & $2\left({ }^{*} 0\right)$ \\
\hline Total & 202 & $134(66 \%)$ & $170(80 \%)$ & $73(36 \%)$ & $28(14 \%)$ & $26\left(^{*} 8\right)(13 \%)$ \\
\hline
\end{tabular}
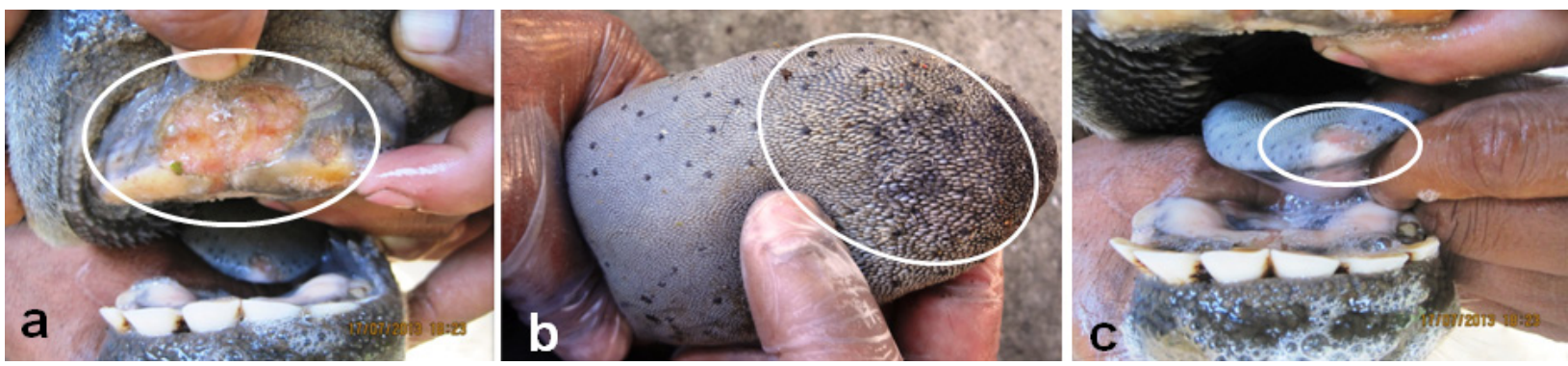

Figure 1. Typically foamy salivation around mouth and ulceration in the gum was seen (a, circle) in infected cattle. The lingual papilla of early infected cattle showed degeneration and disorganization ( $b$, circle). Vesicle developed onto the surface of tongue ruptured readily, leading to the formation of ulcer (c, circle).
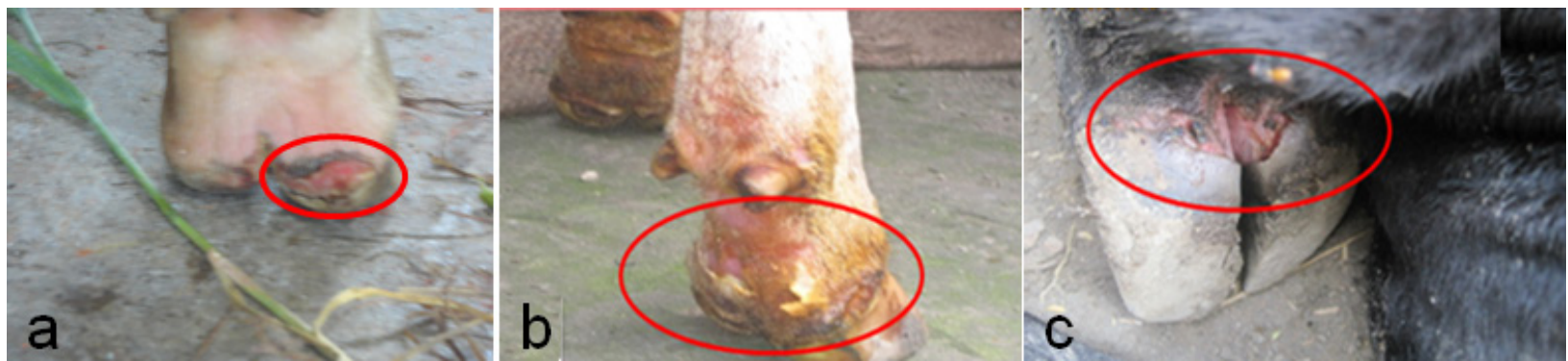

Figure 2. Clinical manifestation of FMD in the foot. Vesicular eruption, erosion and sloughing off skin over the interdigital skin (a and b, circle) was seen in infected cattle. In advanced and complicated cases the hoofs were separated from its underlying tissues (c). 


\subsection{Pathological Investigation}

Out of 35 young calves (below six months) and $167 \mathrm{semi}$ mature (six months to 2 years) to adult cattle investigated, 18 young calves (Figure $3 \mathrm{a}$ and $3 \mathrm{~b}$ ) and 08 semi mature to adult cattle (Figure $3 \mathrm{c}$ ) were died due to FMD. Infected and dead calves $(n=07)$ and semi-mature to adult cattle $(n=02)$ were investigated at necropsy to find out the causes of death. Vesicular eruption and erosions in hooves, oral cavity (muzzle, tongue), teat and udder (Figure 4a) were noticed in the elderly cattle. The udder tissues of dead cows revealed fibrosis and consolidation (Figure $4 \mathrm{~b}$ and $4 \mathrm{c}$ ).
Young dead calves revealed scanty lesions at oral and pedal tissues. Myocardial lesion was common in all the dead young and adult cattle investigated; the irregular grey necrotic foci onto the heart gave rise to a stripped appearance commonly known as 'tiger heart' disease (Figure 5a). Characteristic "currant jelly clot" was seen in the heart of adult cattle (Figure 5b). Congested and consolidated lungs (Figure 6a) and atrophy of spleen (shrinkage of the capsule) was seen in adult cattle. Hemorrhages were seen in the pancreas of elderly dead cattle.

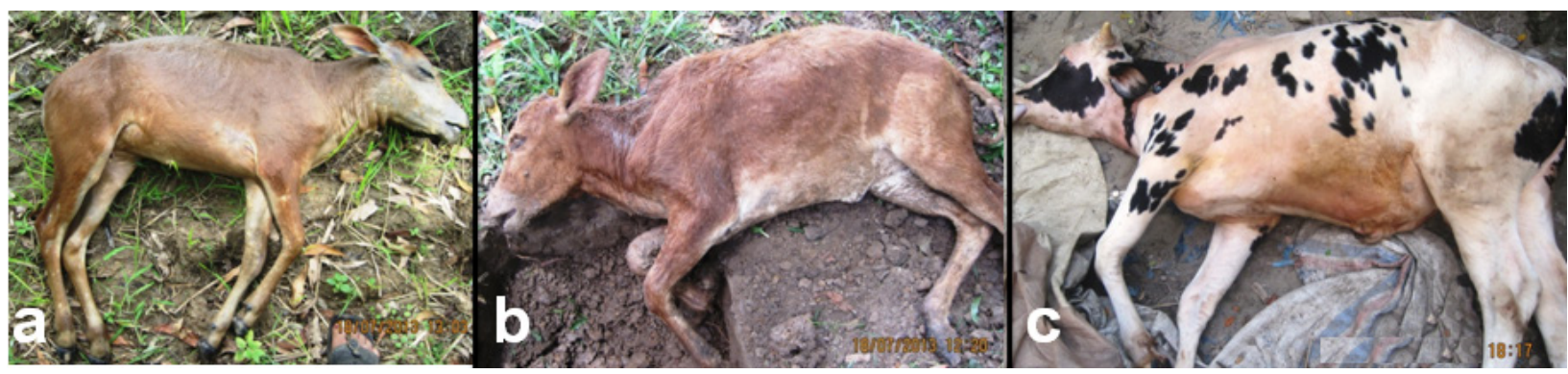

Figure 3. The rate of mortality appeared higher in infected young calves (a and b). Out of 35 young calves infected, 18 were died. Case fatality in semi-mature cattle was seen (c) following natural infection with FMD virus.
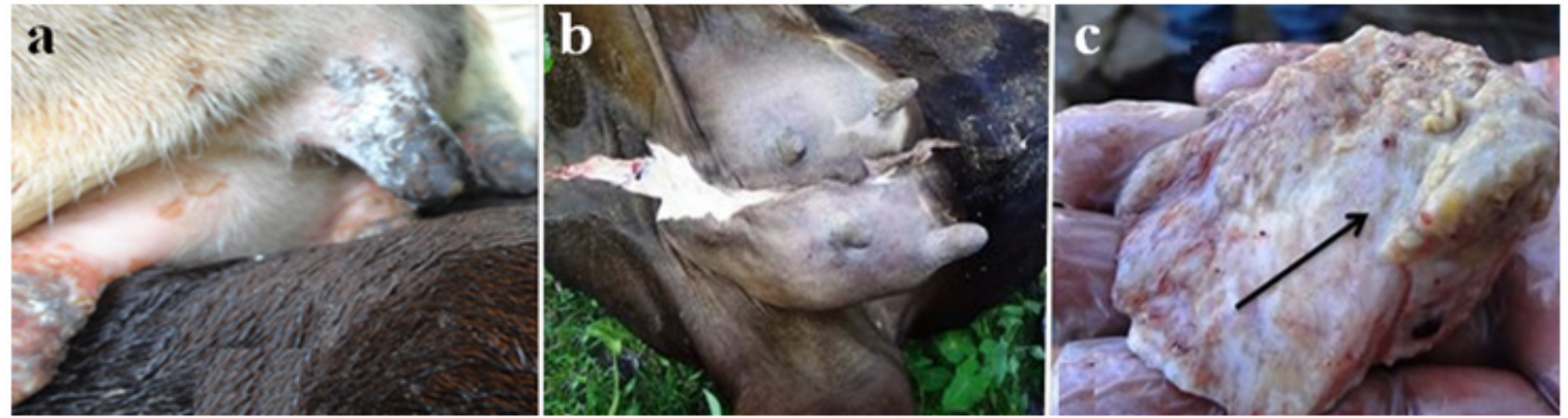

Figure 4. Clinicopathological investigation of FMD in the udder of infected cows. Vesicular eruption and erosion in the skin of teat and udder was seen in an infected cow (a). The udder of infected cow appear inflamed and fibrosed (b, c).
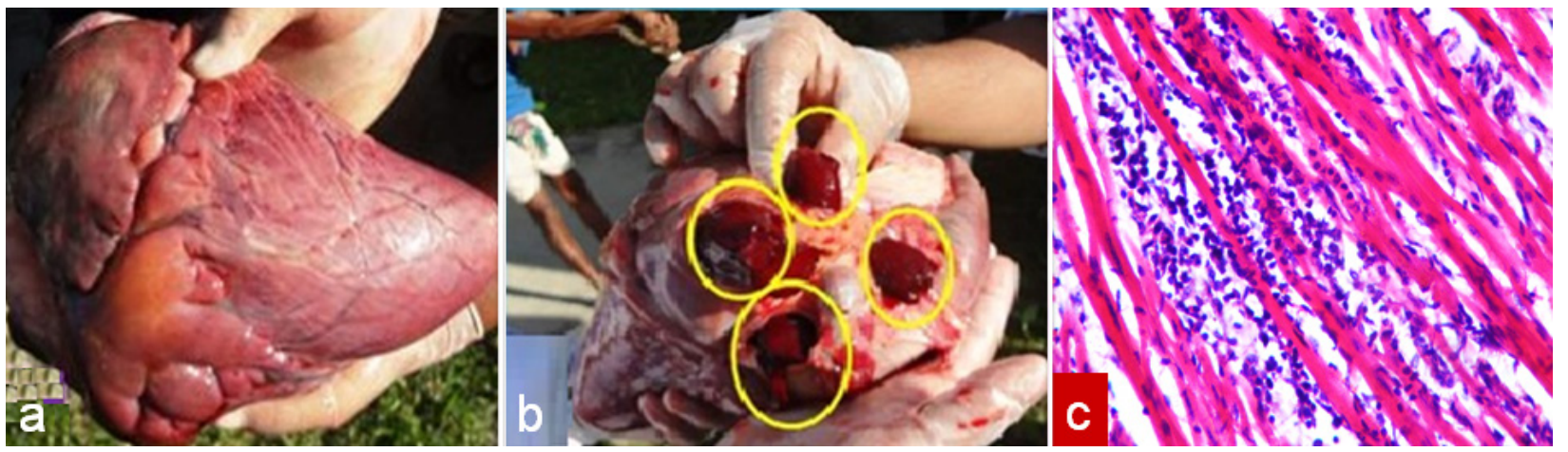

Figure 5. Lesion specific to 'tiger heart disease' was seen in the heart of an infected and death calf (a). Post mortem clot popularly known as 'currant jelly clot' (b, yellow circle) was seen in the large vessels originating from the heart. Section of heart muscle stained with H\&E showed focal necrosis and infiltration of mononuclear cells (c, 40x). 


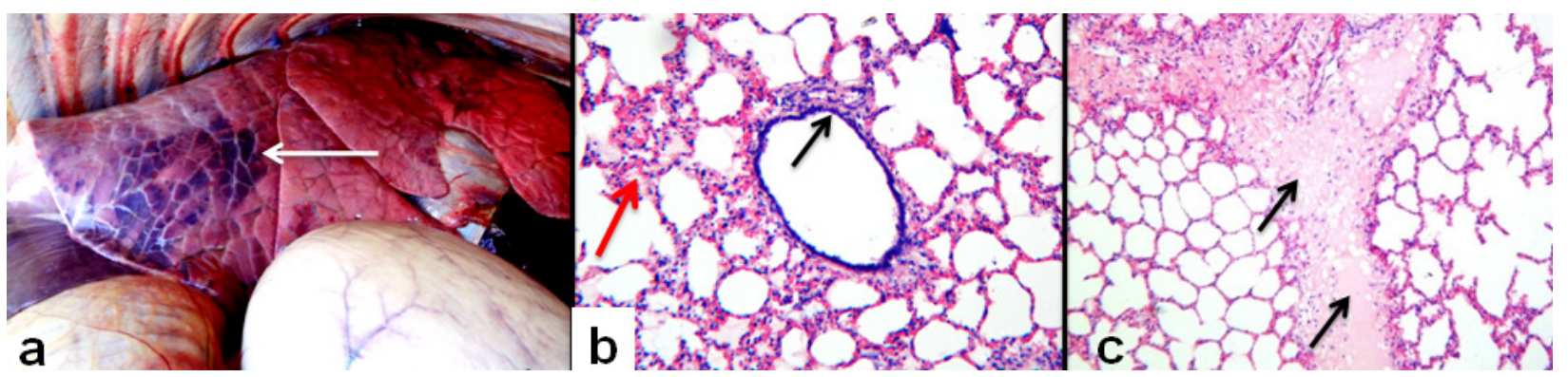

Figure 6. The lungs of infected adult cattle (a) showed congestion and consolidation (arrow). The sections of lungs stained with H\&E (b, 10x) showed bronchiolitis (black arrow) and interstitial pneumonia (red arrow). The interlobular septa of lungs appeared muck thicker due to deposition of fibrin and hemorrhages (c, arrows, 10x).

Specific and characteristics histopathological lesions were observed in the oral, pedal, cardiac and lung tissues. Most striking lesions seen were in the heart muscles of both the young and adult cattle, where the muscle fibers were necrosed and hyalinised. Multifocal accumulation of lymphocytes was seen in necrotic heart muscle (Figure 5c). Vesicle formation and ulcerative lesions with edema and degeneration were seen both in the pedal (Figure 7) and oral (Figure 8) tissues. There were emphysema, interstitial pneumonia (Figure 6b) and thickening of interlobular septa of lungs (Figure $6 \mathrm{c}$ ). Lymphoid depletion in spleen and enlargement of splenic trabeculi was seen in adult cattle (Figure 9a). Multifocal hemorrhages and lymphocytic infiltration was observed in pancreas. The tongue muscle showed focal accumulation of mononuclear cells (Figure 9b). Hemorrhages and congestions were commonly noted in the duodenum of infected and dead cattle (Figure 9c).
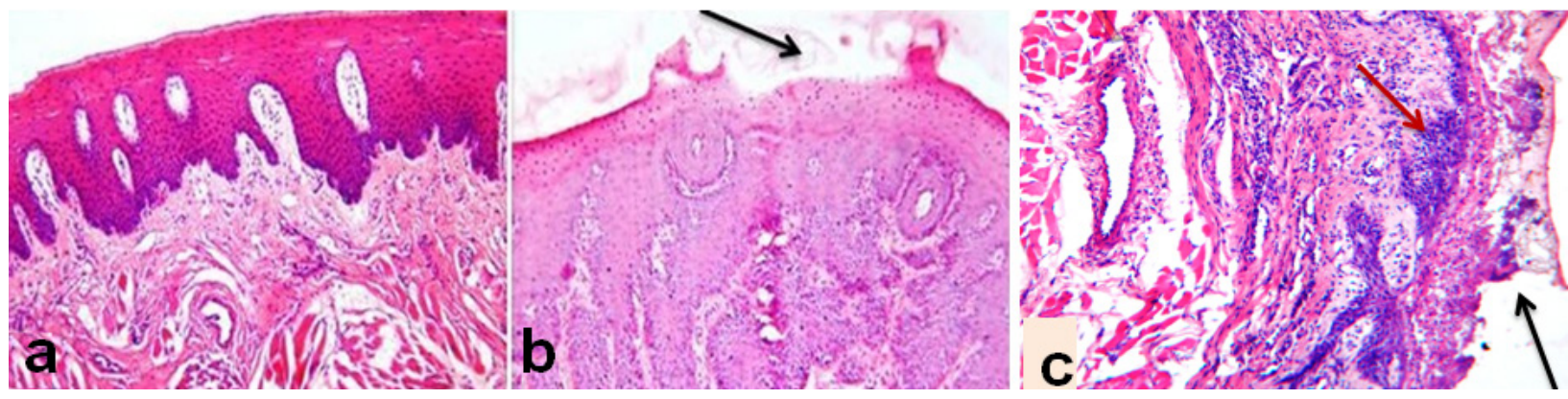

Figure 7. Under microscopic examination, micro-vesicle and ulceration were seen into the epidermis of interdigital skin (b, black arrow, $4 \mathrm{x})$. The stratum corneum of interdigital skin (c) of severely infected cattle was sloughed off (black arrow) and the denude dermis was infiltrated with profuse mononuclear cells (c, red arrow, 10X), which however, was absence in the healthy skin (a).

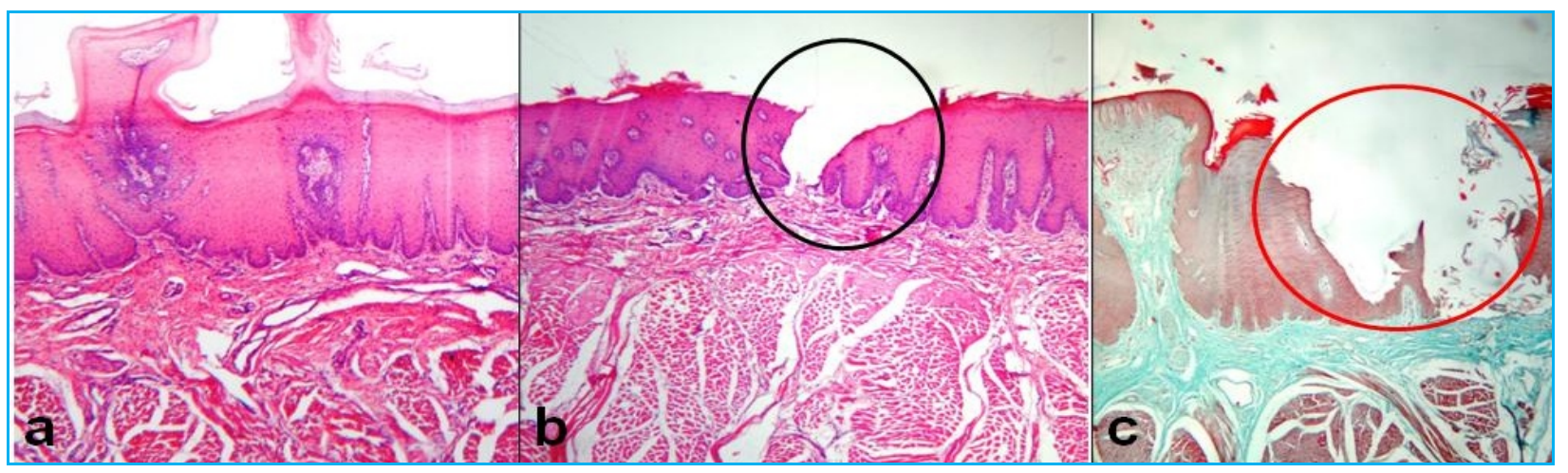

Figure 8. Investigation of the sections of control (a) and infected ( $b$ and c) tongue stained with H\&E (a and b, 10x) and Goldner's Trichrome (c, 4x). Formation of vesicles (black and red circle) with disruption of squamous epithelium (circles, $b$ and $c$ ) was seen in the tongue epithelium of infected cattle. 


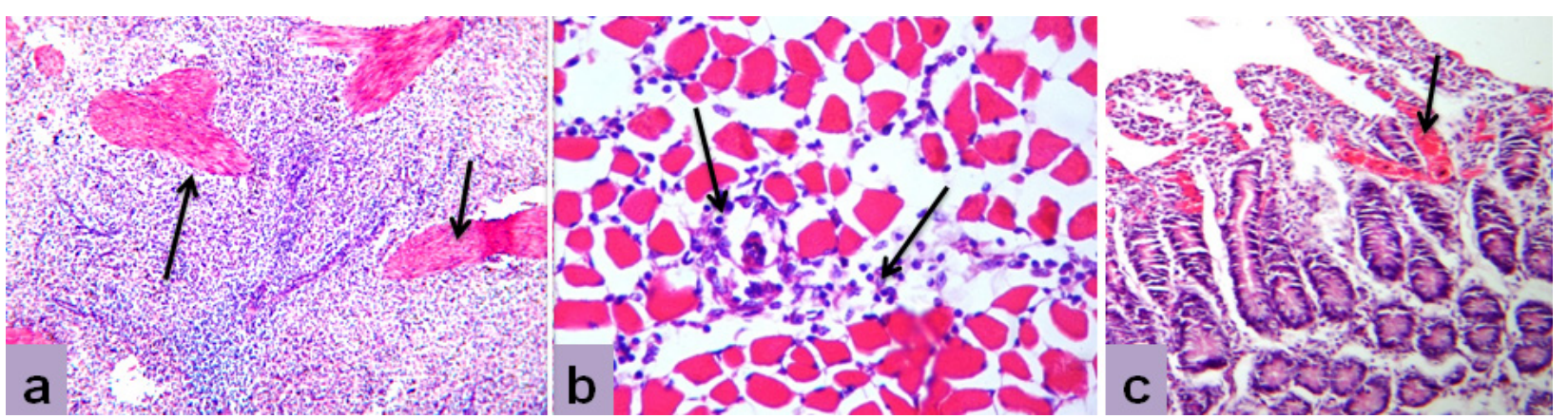

Figure 9. Section of spleen stained with $\mathrm{H} \& \mathrm{E}(\mathrm{a}, 10 \mathrm{x})$ showed lymphoid depletion and enlargement of splenic trabeculi (arrow). Interestingly mononuclear cellular infiltration was seen in the tongue muscle (b, arrow, 40x) of infected cattle. Congestion and hemorrhages (c, arrow) were seen in the duodenal mucosa of infected cattle.

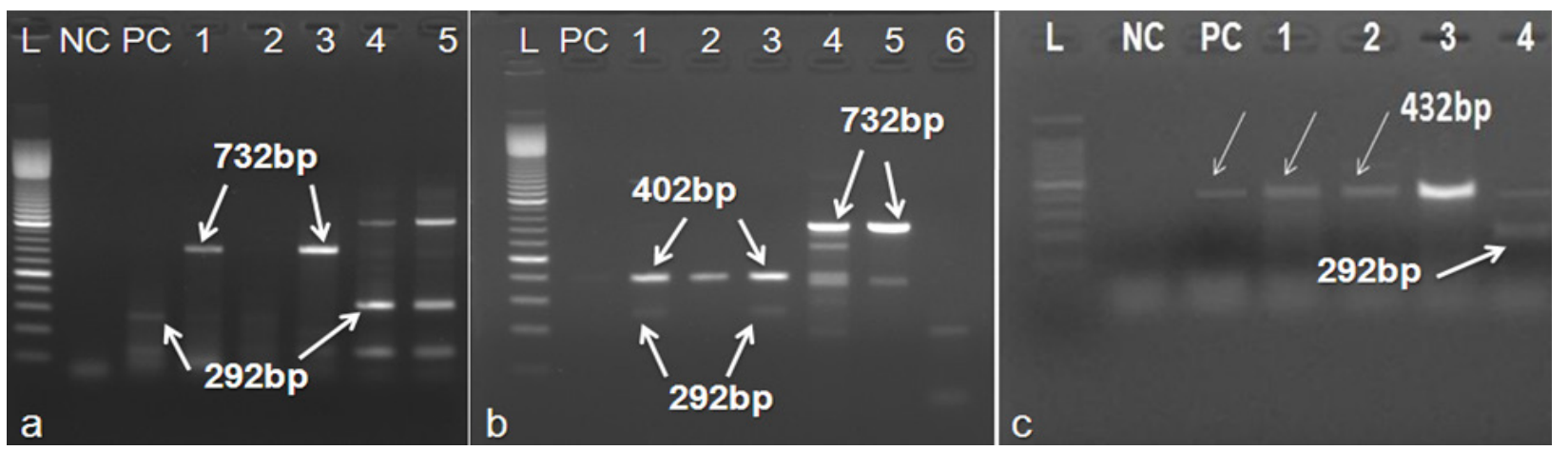

Figure 10. Multiples RT-PCR detection of FMD viral serotypes with the extracted RNA ( $\mathrm{n}=202)$ from the oral lesions of infected cattle. The lane L is for $100 \mathrm{bp}$ ladder, $\mathrm{NC}$ is for negative control, PC is for positive control and lane 1 to 6 are test samples. The amplification of 292 , 402 and $732 \mathrm{bp}$ amplicons in RT-PCR were specific for infectivity due to FMD viral serotype O, A and Asia-1 respectively.

\subsection{Identification of FMD Viral Serotype}

Out of 202 samples tested in multiplex RT-PCR, 187 samples found to generate amplification reaction for FMD viral serotypes. Amplification of 402bp, 732bp and 292bp fragments in RT-PCR were suggestive for infectivity due to FMD viral serotype O, A and Asia-1 respectively (Figure 10). Among the FMD viral serotype specific positive identification, single infectivity due to FMD viral Serotypes O, A and Asia 1 were seen in 115 (62\%), 26 $(14 \%)$ and $34(18 \%)$ cases respectively. Seven cattle were co-infected with FMD viral Serotypes O and Asia 1 and four with FMD viral Serotypes O and A. FMD viral serotype $\mathrm{O}$ was dominating all over the country followed by Asia1 and A. FMD viral serotype $\mathrm{C}$ still remain undetected in Bangladesh.

\section{Discussion}

Foot and Mouth Disease (FMD) is a transboundary animal disease which affects all cloven-hoofed domestic animals including cattle, sheep, goats, pigs, and buffalo. Outbreak of FMD imposed restriction on global tread of animals and its products [18]. The disease is characterized clinically by fever, lameness and vesicular lesions on the mouth, tongue, feet, snout and teats of infected animals [19]. The serotype identification of FMD viruses is needed to know the circulating virus and to design effective preventive strategy. The present study exclusively illustrated the clinicopathological changes following natural outbreak of FMD in cattle of Bangladesh and the serotypes involved in the disease process was identified.

The clinical signs and gross lesions observed during outbreak investigation and necropsy were very much suggestive for clinical diagnosis of FMD. Characteristic signs and lesions observed were salivation, vesicular lesion in foot and mouth, lameness, ulceration, maggot infestation in sore legs, smacking of the lips, grinding of the teeth, nasal discharge, shaking/kicking of the feet which were consistent with previous studies [20,21,22]. Characteristic myocardial lesion commonly known as 'tiger heart disease' was seen in the infected and death cattle. The necrotic lesions in heart make it incapable to pump out blood throughout the body leading to the development of 'currant jelly clot' in the heart and its larger vasculature. Consolidated lungs was also found during necropsy as described earlier [19, 23], it was due to secondary bacterial infection, predominantly Pasteurella spp (data was not shown).

The acute myocarditis of young animals is distinguished by hyaline degeneration, necrosis of muscle fibers and infiltration of fewer lymphocytes [14]. Histopathological examination of heart of adult cattle revealed hyaline degeneration and multifocal necrosis with accumulation of 
huge lymphocytes. It may be due to fact that the young calves got little time to survive following cardiac necrosis and hence there were deposition of fewer lymphocytes. The adult cattle died three to four days after infection, had time to combat but died due to wide spread necrosis of heart muscle; massive infiltration of reactive cells were, therefore, evident in the necrotic heart muscle. Interstitial pneumonia and thickening of interlobular septa of lungs with fibrinous exudates was seen in adult cattle. The respiratory distress was seen in some of the infected and recovered cattle [3] may be due to interstitial pneumonia and thickening of interlobular septa that ultimately reduced space for alveoli to expand and finally contributed ill participation of lungs alveoli in gaseous exchange. Other noticeable histopathological lesions viz. ballooning degeneration and vesicle formation in the affected skin, congested and hemorrhagic spleen (acute cases) and intestine (acute cases), depletion of lymphocytes in spleen (chronic cases), disruption of squamous epithelium with lymphocyte infiltration in tongue muscle found in this study appeared characteristics [24]. New information is that the pancreas of infected cattle showed hemorrhages and focal lymphocytic infiltration, this may contribute digestive disorders or diabetes in survivor cattle. The lesions seen in the tongues of infected cattle mostly confined to the anterior quarter.

It is not difficult to identify FMD by observing clinical signs in natural outbreaks but the serotyping of FMDV is the troublesome and is needed to establish effective preventive measure. In this study, samples were collected from a total of 202 infected cattle to identify FMD viral serotypes using multiplex RT-PCR. Among 202 field samples, previously we have tested 92 samples in multiplex RT-PCR and detected FMD viral serotypes in 90 cases [17]. This study investigated all the samples $(n=202)$ in RT-PCR detection of FMD viral serotypes and found to generate 292bp, 402bp and 763bp amplicons specific for FMD viral serotypes O, A and Asial in 115 (62\%), 26 $(14 \%)$ and $34(18 \%)$ cases respectively. This study identified FMD viral serotypes in 187 (93\%) cases. FMD viral serotype $\mathrm{O}$ was found dominating in all seven divisions of the country investigated. Recently a different observation was noted in Bangladesh and reported a dominancy of FMD viral serotype A over Asia1 [25]; this might be due to differences in the coverage of sample collection areas. Infectivity of cattle due to FMD viral serotypes O (80\%), A (8\%) and Asia1 (12\%) in India was reported during April 2006 to March 2011[26], where FMD viral serotype $O$ was also dominated. FMD viral serotypes $\mathrm{O}, \mathrm{A}$ and Asia1 are consistently circulating in Bangladesh, Bhutan, India, Nepal, and Sri Lanka (Pool 2) with a dominancy of viral serotype O [27].

\section{Conclusions}

FMD is clinically characterized by salivation, vesicular lesion, lameness and maggot infestation smacking of the lips, grinding of the teeth, nasal discharge, shaking/kicking of the feet, mastitis etc. Characteristics myocardial lesion popularly known as 'tiger heart disease' was common in cattle died due to FMD. The 'currant jelly clot' was found in heart of adult cattle and was due to chronic heart failure. Pathologically the disease is characterized by necrotic changes in heart muscles, vesicular lesions in foot and mouth, interstitial pneumonia and hemorrhagic enteritis. Fibrotic mastitis, atrophy of spleen, pancreatitis and glossitis was also evident. The respiratory distress as seen in infected and recovered animals may be due to interstitial pneumonia and fibrinous inflammation in the interlobular septa of lungs. Cardiac myonecrosis and respiratory failure alone or in combination may contribute death of infected cattle. The multiplex RT-PCR protocol adapted is highly (93\%) sensitive to detect FMD viral serotypes in cattle. Cattle in investigating areas were infected predominantly with FMD viral serotype $\mathrm{O}$ followed by serotype Asia 1 and $\mathrm{A}$. The findings of this study may be of value to design future managemental, diagnostic and preventive strategy of FMD in livestock.

\section{Acknowledgements}

Thanks are due to the Krishi Gobeshona Foundation (KGF), Farmgate, Dhaka, Bangladesh for funding the research. Sincere appreciation is also extended to the Department of Pathology, Faculty of Veterinary Science, Bangladesh Agricultural University, Mymensingh-2202, Bangladesh for providing internal resources and laboratory facilities to complete the research.

\section{REFERENCES}

[1] APHIS. Foot-and-Mouth Disease. Factsheet, Veterinary Services, USDA, February 2007 (available at http//www.aphis.usda.gov/ publications/ animal health/).

[2] Biswal JK, Sanyal A, Rodriguez LL, Subramaniam S, Arzt J, Sharma GK et al. Foot-and-mouth disease: Global status and Indian perspective. Indian Journal of Animal Sciences 2012; 82 (2): 109-131.

[3] Brown CC, Olander HJ, Meyer RF. A Preliminary Study of the Pathogenesis of Foot-and-mouth Disease Virus sing in situ Hybridization. Veterinary Pathology1991; 28: 216-222.

[4] Chowdhury MMR, Hossen ML, Ahmed S, Nazir KHMNH, Rahman M, Khan MFR, Amin KB, Rahman MT and Rahman MB.. Preparation of Inactivated Trivalent FMD Vaccine and Determination of Antibody Titer in Vaccinated Cattle. International Journal of Tropical disease \& Health 2016; 16(2): 1-8.

[5] Rubina AA, Monzoor H, Amer BZA, Hamid I, Umer. Epidemiological analysis of foot and mouth disease in 
Pakistan. International Journal of Agriculture and Biology 2002; 8(5):648-651

[6] James AD, Rushton J. The economic s of foot-and-mouth disease. Revue Scientifique-et-Technique, Office International des Epizooties 2002; 21: 637-644.

[7] Islam MS, Ruba T, Habib MA, Rima UK, HossainMZ, Saha PC, Das P, Khan, MAHNA. Sequencing and Translational Analysis Revealed Huge Mutation in the N-Terminus End of Leader Proteinase (Lpro) Gene of Foot and Mouth Disease Viruses Isolated From Cattle in Bangladesh. IOSR Journal of Agriculture and Veterinary Science (IOSR-JAVS) 2016; 9(2): 24-30.

[8] Chowdhury SMZH, Rahman MF, Rahman MB, Rahman MM. Strains of foot and mouth disease virus in different districts of Bangladesh. Asian-Australian Journal of Animal Sciences 1996;9: 315-317.

[9] Marquardt O, Rahman MM, Freiberg B. Genetic and antigenic variance of foot-and-mouth disease virus type Asia1. Archives of Virology 2000;145: 149-157.

[10] Freiberg B, Rahman MM, Marquardt O: Genetic and immunological analysis of recent Asian type $\mathrm{A}$ and $\mathrm{O}$ foot-and-mouth disease virus isolates. Virus Genes 1999;19: $167-182$.

[11] Islam MA, Rahman MM, Adam KH, Marquardt O. Epidemiological implications of the molecular characterization of foot-and-mouth disease virus isolated between 1996 and 2000 in Bangladesh. Virus Genes 2001;23:203-210.

[12] Loth L, Osmani MG, Kalam MA, Chakraborty RK, Wadsworth J, Knowles NJ, Hammond JM, Benigno C. Molecular Characterization of Foot-and-Mouth Disease Virus: Implications for Disease Control in Bangladesh. Transboundary and Emerging Diseases 2011;58:240-246.

[13] Mason GL, Madden DJ.Performing the field necropsy examination. The Veterinary Clinics of North America. Food Animal Practice 2007; 23(3): 503-26

[14] Luna L. Manual of Histologic Staining Methods of the Armed Forces Institute of Pathology, New York.1968.

[15] Khan MAH, Ogita H, Ferro VA, Kumasawa K, Tsutsui T, Kimura. Immunisation with a plasmid DNA vaccine encoding gonadotrophin releasing hormone (GnRH-I) and T-helper epitopes in saline induces an anti-GnRH-I antibody response and suppresses rodent fertility. Vaccine 2008;26(10):1365-1374.
[16] Vangrysperre W, De Clercq K. Rapid and sensitive polymerase chain reaction based detection and typing of foot and mouth disease virus in clinical samples and cell culture isolates, combined with a simultaneous differentiation with other and/ or symptomatically related viruses. Arc Virol 1996; 141: 331-344.

[17] Islam MS, Habib MA, Saha PC, Das PM, Khan MAHNA. Distribution of foot and mouth disease virus serotypes in cattle of Bangladesh. SAARC J Agric 2017; 15(1): 33-42.

[18] OIE. Foot-and-mouth disease. In: OIE Manual of standards for diagnostic tests and vaccines for Terrestrial Animals. $6^{\text {th }}$ Edn. Office international des Epizooties, Paris, France.2008; Chapter 2.1.5: 77-92.

[19] Alexandersen S, Zhang Z, Donaldson AI, Garland AJM. The pathogenesis and diagnosis of foot and mouth disease. Journal of Comparative Pathology 2003;129:1-36.

[20] Sahle M. An epidemiological study on the genetic relationships of foot and mouth disease viruses in east Africa. University of Pretoria, South Africa, Pretoria, PhD Thesis.2004; 84-107.

[21] Kitching RP, Alexandersen S: Clinical variation in foot and mouth disease: pigs. Revue Scientifique-et-Technique, Office International des Epizooties 2002;21: 513-518.

[22] OIE. Foot-and-mouth disease. In: Mannual of standards for Diagnostic Tests and Vaccines for Terrestrial Animals. Paris, 2000 .

[23] Burrows R, Mann JA, Garland AJM, Greig A, Goodridge D: The pathogenesis of natural and simulated natural FMD infection in cattle. Journal of Comparative Pathology1981;91: 599-609.

[24] Radostits OM, Blood DC, Gay CC.Veterinary Medicine, 8th edition. London: Bailliere and Tindall. 1994:pp. 345-372.

[25] Hossen ML, Ahmed S, Khan MFR, Rahman MT, Saha S, Nazir KHMNH, Rahman M., Islam MA, Rahman MB. Typing of Foot and Mouth Disease Virus Circulating in Bangladesh by Reverse Transcription Polymerase Chain Reaction. Journal of Veterinary Advances 2014; 4(12):778-785.

[26] Subramaniam S, Pattnaik B, Sanyal A, Mohapatra JK, Pawar SS, Sharma GK, Das B, Dash BB. Status of Foot-and-mouth Disease in India. Transboundary and Emerging Diseases 2013; 60:197-203.

[27] FAO. Food and Agriculture Organization of the United Nations, Foot-and-Mouth Disease Situation, Monthly Report, November, 2015. 